Tree roost selection by bats: an empirical synthesis using meta-analysis

Matina C Kalcounis-Rüppell; Jennifer M Psyllakis; R Mark Brigham

Wildlife Society Bulletin; Fall 2005; 33, 3; Research Library

pg. 1123

\title{
Tree roost selection by bats: an empirical synthesis using meta-analysis
}

\author{
Matina C. Kalcounis-Rüppell, Jennifer M. Psyllakis, and \\ R. Mark Brigham
}

\begin{abstract}
Over the past 2 decades, we have begun to accumulate a basic understanding of the roosting and foraging ecology of temperate insectivorous bats in forests. As our understanding improves, it is not surprising there should be attempts at synthesizing our knowledge to prioritize future research directions (e.g., Hayes 2003, Miller et al. 2003). Miller et al. (2003) reviewed results of 56 papers (1980-2001) and concluded that current data were unreliable because of small sample sizes, the short-term nature of studies, pseudoreplication, inferences beyond the scale of data collected, study design, and limitations of bat detectors and statistical analyses. Our concern is that this type of narrative synthesis that highlights limitations ignores any quantitative patterns that may exist. In this study we assess whether general patterns in North American bat use of roost trees and stand characteristics are robust enough to distill from the published literature. We used a series of meta-analyses on the same set of studies cited by Miller et al. (2003) to assess whether limitations of the current data warrant exclusion of bats from management recommendations. We used a second series of meta-analyses incorporating more recent data to determine the best current synthesis of knowledge on bat use of forests for roosting. In a third and fourth series of meta-analyses, we separated studies done on bats roosting in cavities versus roosting in foliage. In general, we found that, relative to other trees in the forest, the roost trees of bats were tall with large DBH in stands with open canopy and high snag density. In contrast, roost trees of bats did not differ from random trees with respect to live-tree density. The main differences we detected between foliageand cavity-roosting bats were in percent canopy cover and distance to water. The roost trees of cavity-roosting species had more open canopies and were closer to water than random trees. Our results clearly show that significant patterns can be detected from the literature when data sets are combined using a meta-analytic approach.
\end{abstract}

Key words bats, Chiroptera, forest-roosting bats, habitat management, meta-analysis, North America, roost selection, roosts

\begin{abstract}
North American Symposium on Bat Research revealed that beginning in the early 1990 s there was a substantial increase in the number of presentations about interactions between North American insect-eating bats and forests, specifically how bats use trees as roost
\end{abstract}

structures. This was closely followed with a substantial number of papers published in peerreviewed literature culminating in the first symposium dedicated to the topic of bats and forests (Barclay and Brigham 1996). This change appears to have been driven by the realization that until the

Address for Matina C. Kalcounis-Rüppell: Department of Biology, University of North Carolina at Greensboro, P.O. Box 26170 Greensboro, NC 27402-6170, USA; e-mail: matina_kalcounis@uncg.edu. Address for Jennifer M. Psyllakis: Department of Natural Resources and Environmental Sciences, University of Northern British Columbia, Prince George, BC V2N 4Z9, Canada. Address for R. Mark Brigham: Department of Biology, University of Regina, Regina, SK S4S OA2, Canada. 


\section{Wildlife Society Bulletin 2005, 33(3):1123-1132}

early 1990s, the vast majority of work on North American bats during the active season focused on colonies in buildings, caves, and mines, despite the fact that more than half of all bats spend at least part of their lives roosting in trees. This coincided with technological innovations that reduced research limitations associated with the small body size of many species of North American bats.

With the maturation of a field of inquiry should come attempts at synthesis to distill general patterns so that future work can become more focused on issues of importance (Arnqvist and Wooster 1995). Given the considerable body of work over the past decade that has addressed the use of forest roosting habitat by temperate insectivorous bats, synthesis now is possible and important. Much of these data were collected to answer basic questions of natural history, and studies were not specifically designed to provide recommendations to forest managers on how to improve or maintain habitat characteristics for bats in managed forests. A quantitative synthesis of these studies can help forest managers by presenting overall trends in roost-habitat characteristics of forest bats.

Hayes (2003) qualitatively synthesized a significant body of published literature on the interaction between bats and forests in the Pacific Northwest region of North America. The review focused on advances that have occurred over the past decade in our understanding of how bats use forest resources. While there were useful suggestions from the perspective of forest management, this was clearly not the major objective of the review. Hayes (2003) concluded there were some robust general conclusions about types of trees bats use as roosts and suggested directions for further research that would enhance our knowledge of bats.

Another qualitative review of 56 published papers by Miller et al. (2003) focused on forest management issues that result from bat interactions with trees throughout North America. One general suggestion of Miller et al. (2003) was that our current knowledge is too uncertain to be of direct use to forest managers trying to incorporate bats into management plans. Without stating it explicitly, Miller et al. (2003) asserted that most or all of the current "uncertainties" about roost selection by forest bats result primarily from statistical and methodological problems and could be corrected with better-funded, longer-term studies founded on direct partnerships between forestry companies and biologists. The authors tempered this senti- ment in their conclusions and argued that the current literature is useful but again stressed that study design and statistical treatment need to be improved in future studies.

The objective of our study was to provide the first quantitative synthesis of literature about how bats use tree roosts in forests with a view to clarify issues for both biologists with an interest in bats and forest mangers attempting to incorporate these animals into forest management plans. We recognize that incorporating uncertainty into harvest and management prescriptions can be difficult. Nonetheless, harvesting continues and therefore many biologists and ecologists are faced with the difficult task of making recommendations based on the best available data, which, as Miller et al. (2003) pointed out, is not necessarily the same as the best possible data. Johnson (2002) argued convincingly that even marginal original data are useful in metaanalytic evaluations given the importance of replicating ecological data.

Our specific purpose was twofold. First, we used a series of meta-analyses on the same set of 56 studies to assess whether general patterns in bat selection of roost tree and stand characteristics could be distilled from the literature. We used a second series of meta-analyses incorporating more recent data to determine the best current synthesis of knowledge on bat use of forests for roosting. We used a third and fourth series of meta-analyses to separate the studies done on bat species that roost in cavities from those that roost in foliage because of inherent differences in the roosting behavior of these 2 groups (Kunz and Lumsden 2003).

Meta-analysis is a statistical technique used in ecology that affords comparisons among multiple studies by standardizing statistical tests of hypotheses from each study (Gurevitch et al. 2001). The comparable metric for this comparison is the effect size that can be calculated regardless of the statistical test of hypothesis used. The benefits of using meta-anaylsis are that it is a quantitative technique in which hypotheses can be tested and patterns over multiple studies can be summarized. By its quantitative nature, it is more informative than descriptive reviews (Arnqvist and Wooster 1995). Despite these benefits, there are problems associated with the technique, including publication bias toward studies that demonstrate significant differences, problems associated with combining studies that tested hypotheses with different designs, and pseudoreplicaton that arises from selecting mul- 
tiple data sets from a single study (Osenberg et al. 1999). We avoid the problem of combining different study designs by looking only at studies that used the same design. We avoid the problem of publication bias by examining studies from the past 2 decades, which represented the beginning of research on forest bats when there was a paucity of data that precluded publication bias. We do not avoid the problem of pseudoreplication because we feel the benefits of examining as many species of bats, in as many forest types as possible, outweigh the potential problems associated with taking multiple data sets from single studies.

\section{Methods}

For our meta-analyses we extracted information from the literature on the following 6 commonly measured variables: tree diameter at breast height $(\mathrm{DBH})$, tree height, distance from the tree to nearest water source, percent closure of the canopy of the tree, density of live trees in the vicinity of the tree, and density of snags in the vicinity of the tree. For consistency and direct comparison in our metaanalyses, we only included studies presented in Miller et al.(2003) that were explicit comparisons of roost vs. random trees. In addition, we examined subsequently published papers, reports, unpublished Ph.D. dissertations, and unpublished M.S. theses not included in Miller et al. (2003). We further subdivided the complete set of data into those studies done on cavity-roosting bats and those studies done on foliage-roosting bats because of inherent differences in the roosting biology of foliage- and cavity-roosting bats (Kunz and Lumsden 2003).

The scale of the roost vs. random comparison (e.g., within a plot, stand, or landscape) varied among studies examined. Before conducting a meta-analysis, we converted all measures of size and distance to the same units (centimeters, meters, and kilometers) and converted all measures of density to number of trees or snags per hectare. From each study, we extracted mean, standard deviation, and sample size for both roost and random trees. We considered each study a single data set except for those that reported more than one set of results (e.g., data reported by study site, species, or sex). In these studies we considered each set of results as an independent data set.

Every data set had information for at least one of the 6 tree variables. For all variables in every data set, we calculated effect sizes as standardized mean differences. In all cases we calculated standardized mean difference as the mean difference between the mean of the roost tree group and the mean of the random tree group divided by the pooled within group standard deviations. The combined estimate of the effect size was calculated as the weighted mean of the effect sizes from all the included data sets. Throughout our analysis and manuscript, sample size refers to number of trees in a roost or random group (as opposed to number of bats).

For each variable, we a priori predicted a direction of the outcome. The direction of our predicted outcome was required to be consistent in each study, but the predicted direction did not affect the analysis. Rather, the direction was necessary for interpretation of the results in so far as the direction of the recalculated effect size ( + or -$)$. Based on the biology of bats and descriptions from the literature, we predicted the following: $\mathrm{DBH}$ and height of roost trees would be larger than random trees; roost trees would be closer to water than random trees; roost trees would have a more open canopy than random trees; snag density would be higher around roost trees than random trees; and live-tree density would be lower around roost trees compared to random trees. Because our purpose was to look for unambiguous patterns in existing literature, we were conservative and accepted a result as significant only if the recalculated $P$-value from the combined set of data was less than 0.01 . To conduct the meta-analyses, we used the program Comprehensive Meta-analysis (Biostat ${ }^{\circledR}$ 19972000) and treated data as described above.

\section{Results}

Of the 56 articles cited by Miller et al. (2003), 28 explicitly dealt with tree roost selection by bats. These studies span species and likely included geographic variation across North America. Of the 28 articles, 15 allowed us to extract the necessary data to perform a meta-analysis on at least one of 6 variables (Table 1). Of these 15 articles, 5 contained more than one data set; this resulted in a total of 22 data sets for use in the analysis. We detected a significant pattern from this body of literature for 3 of 6 variables. Relative to random trees, roost trees had larger DBH $\left(n_{\text {data sets }}=18, n_{\text {roost }}=484, n_{\text {random }}=\right.$ $1,189$, effect size $=0.77, P<0.001)$, were taller $\left(n_{\text {data }}\right.$ sets $=15, n_{\text {roost }}=454, n_{\text {random }}=948$, effect size $=0.85$, $P<0.001$ ), and were in areas with a more open canopy $\left(n_{\text {data sets }}=15, n_{\text {roost }}=413, n_{\text {random }}=851\right.$, 


\section{Wildife Society Bulletin 2005,33(3):1123-1132}

Table 1. Literature reviewed by Miller et al. 2003 and used in our meta-analyses.

\author{
Barclay et al. 1988 \\ Betts 1998 \\ Brigham et al. 1997 \\ Callahan et al. 1997 \\ Campbell et al. 1996 \\ Grindall 1999 \\ Hutchinson and Lacki 2000 \\ Kalcounis and Brigham 1998 \\ Lacki and Schwierjohann 2001 \\ Menzel et al. 1998 \\ Ormsbee and McComb 1998 \\ Rabe et al. 1998 \\ Sasse and Pekins 1996 \\ Vonhof 1996 \\ Weller and Zabel 2001
}

effect size $=-0.20, P=0.002$ ). There was no difference between density of live trees per hectare ( $n_{\text {data sets }}=9, n_{\text {roost }}=300, n_{\text {random }}=1,039$, effect size $=-0.14, P=0.053$ ) or density of snags per hectare $\left(n_{\text {data sets }}=7, n_{\text {roost }}=273, n_{\text {random }}=453\right.$, effect size $=$ $0.09, P=0.304$ ) between roost and random trees. There was a trend for roost trees to be closer to water than random trees $\left(n_{\text {data sets }}=5, n_{\text {roost }}=221\right.$, $n_{\text {random }}=353$, effect size $=-0.22, P=0.018$ ) but this was not significant.

In addition to the 15 articles encompassing 22 data sets cited by Miller et al. (2003), we found 12 subsequent data sets in one report, 2 In Press manuscripts, 2 publications, and 1 unpublished M.S. thesis that were relevant (Table 2). Thus, in our second set of meta-analyses, we use results from 17 articles, 1 report, and 1 M.S. thesis encompassing 37 data sets. As with the first set of meta-analyses, we found similar patterns but with an additional significant variable (snags per hectare). Relative to random trees, roost trees had larger DBH (Figure $1 ; n_{\text {data sets }}$ $=33, n_{\text {roost }}=1,010, n_{\text {random }}=1,874$, effect size $=$ $0.54, P<0.001$ ), were taller (Figure $2 ; n_{\text {data sets }}=25$, $n_{\text {roost }}=791, n_{\text {random }}=1,443$, effect size $=0.46, P<$ 0.001 ), were in more open canopy (Figure $3 ; n_{\text {data }}$ sets $=22, n_{\text {roost }}=639, n_{\text {random }}=1,248$, effect size $=$ $-0.15, P=0.004$ ), and were in stands with more snags per hectare (Figure $4 ; n_{\text {data sets }}=16, n_{\text {roost }}=$ $704, n_{\text {random }}=1,042$, effect size $=0.39, P<0.001$ ). There was no difference in density of live trees per hectare (Figure $5 ; n_{\text {data sets }}=14, n_{\text {roost }}=491, n_{\text {random }}$ $=1,230$, effect size $=-0.15, P=0.013$ ). Again, there was a trend, albeit not significant, for roost trees to be closer to water than random trees (Figure 6; $n_{\text {data sets }}=7, n_{\text {roost }}=256, n_{\text {random }}=388$, effect size $=$ $-0.18, P=0.032$ ).

Drawing from the complete list of 37 data sets, we also analyzed the data for foliage-roosting bats separately from cavity-roosting bats because of their fundamental differences in roosting behavior. Of the 37 total data sets, 31 were for cavity-roosting bats. As with the previous set of meta-analyses, we found similar patterns but with an additional significant variable (distance to water). Relative to random trees, roost trees of cavity-roosting bats had larger DBH $\left(n_{\text {data sets }}=28, n_{\text {roost }}=858, n_{\text {random }}=\right.$ $1,722$, effect size $=0.50, P<0.001)$, were taller $\left(n_{\text {data }}\right.$ sets $=20, n_{\text {roost }}=639, n_{\text {random }}=1,291$, effect size $=$ $0.40, P<0.001)$, were in more open canopy $\left(n_{\mathrm{data}}\right.$ sets $=19, n_{\text {roost }}=585, n_{\text {random }}=1,023$, effect size $=$ $-0.21, P<0.001$ ), and were in stands with more snags per hectare $\left(n_{\text {data sets }}=15, n_{\text {roost }}=660, n_{\text {ran- }}\right.$ dom $=878$, effect size $=0.44, P<0.001$ ). Additionally, roost trees of cavity-roosting bats were closer to water than random trees $\left(n_{\text {data sets }}=4, n_{\text {roost }}=189\right.$, $n_{\text {random }}=366$, effect size $\left.=-0.29, P=0.008\right)$. There was no difference in density of live trees per hectare $\left(n_{\text {data sets }}=12, n_{\text {roost }}=428, n_{\text {random }}=1,047\right.$, effect size $=-0.09, P=0.18$ ).

Of the 34 total data sets, only 6 were for foliageroosting bats. As we found in the previous metaanalyses, relative to random trees, roost trees of foliage-roosting bats had larger DBH $\left(n_{\text {data sets }}=5\right.$, $n_{\text {roost }}=152, n_{\text {random }}=152$, effect size $=0.84, P<$ $0.001)$ and were taller $\left(n_{\text {data sets }}=5, n_{\text {roost }}=152\right.$, $n_{\text {random }}=152$, effect size $\left.=0.76, P<0.001\right)$. Unlike previous sets of meta-analyses there was a trend for roosts of foliage-roosting bats to be in more closed canopy $\left(n_{\text {data sets }}=3, n_{\text {roost }}=54, n_{\text {random }}=225\right.$, effect size $=0.43, P=0.01$ ). There was no difference in the distance to water between roost and random trees of foliage-roosting bats $\left(n_{\text {data sets }}=3, n_{\text {roost }}=\right.$ $79, n_{\text {random }}=199$, effect size $\left.=-0.01, P=0.94\right)$. There were insufficient data to examine tree and snag density variables for foliage-roosting bats.

Table 2. Literature used in meta-analyses in addition to that reviewed by Miller et al. 2003 (Table 1).

\author{
Arnett and Hayes 2003 \\ Broders and Forbes 2004 \\ Foster and Kurta 1999 \\ Leput 2004 \\ Menzel et al. 2002 \\ Vonhof 1997 \\ Willis and Brigham 2005
}




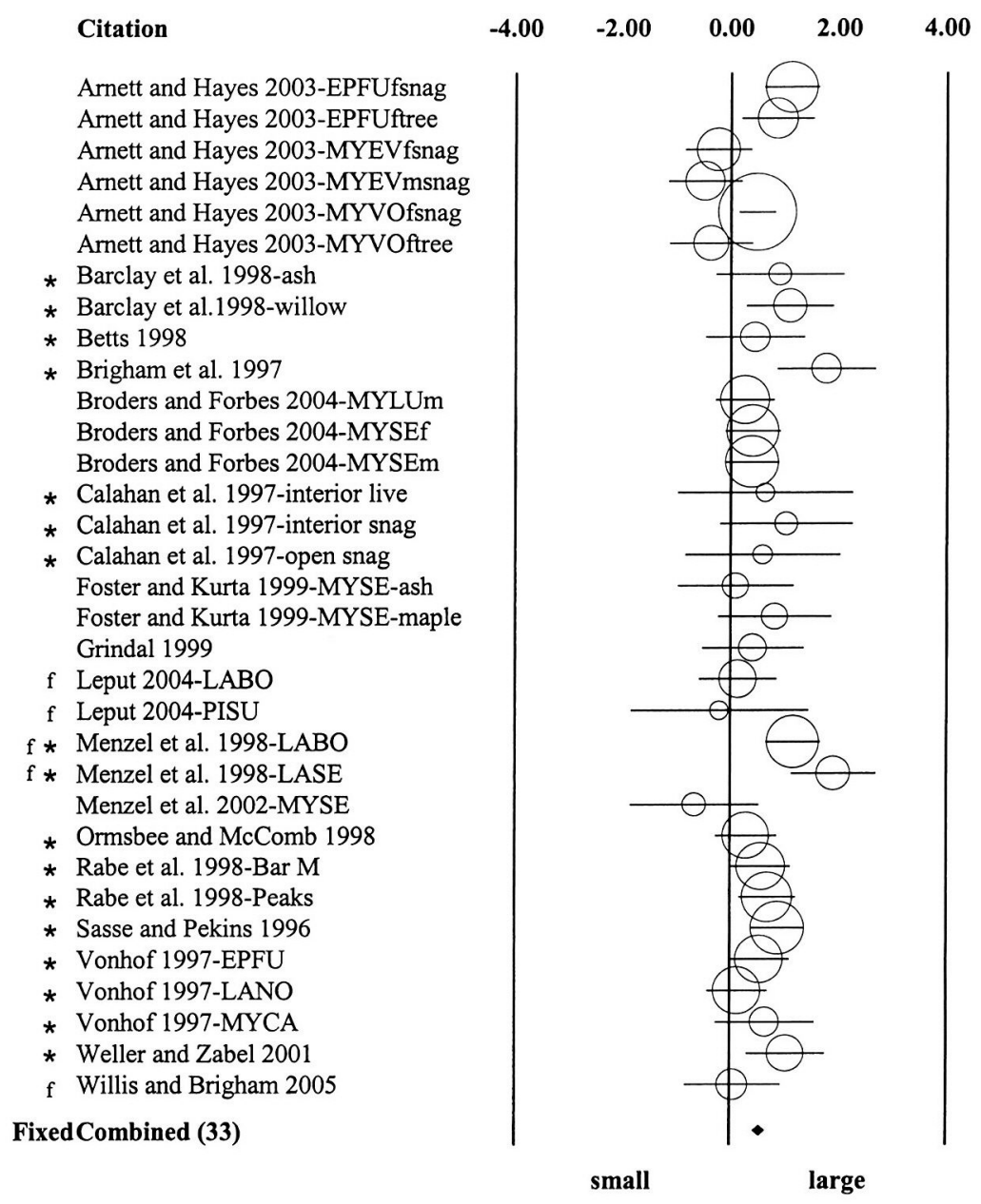

Figure 1. Schematic diagram of the meta-analysis for all studies that examined the DBH of roost and random trees. The effect sizes for each study are plotted as open circles with a 95\% confidence interval of the effect. The diameter of the circle represents the proportional contribution of samples from each study to the combined effect size from the meta-analysis (closed diamond). The centerline represents a zero effect size (no difference between roost and random trees). The definition of the direction of the effect is given underneath each column flanking the zero effect line. Data sets with an asterisk were present in Miller et al. 2003. Data sets with no asterisk were either conducted, published, or incorporated subsequent to Miller et al. 2003. Data sets indicated with an " $\mathrm{f}$ " in front of the citation are for bat species that roost in foliage. Studies without an " $\mathrm{f}$ " in front of the citation are for cavity-roosting species. Information listed after the citation describes the data set from the original paper as follows: EPFU = Eptesicus fuscus, MYEV = Myotis evotis, MYVO = Myotis volans, MYLU = Myotis lucifugus, MYSE = Myotis septentrionalis, MYCA $=$ Myotis californicus, LANO = Lasionycteris noctivagans, $\mathrm{LABO}=$ Lasiurus borealis, LASE = Lasiurus seminolus, PISU = Pipistrellus subflavus, " $f$ " after 4-letter species designate refers to females of that species, " $m$ " after 4-letter species designate refers to males of that species, any other information provided refers to particular site names provided in the paper or particular tree types used. Group sample size, effect size, and $P$-values are provided in the text. Data from Vonhof 1997 are the same as data presented in Vonhof 1996 (cited in Miller 2003).

\section{Discussion}

Our analysis of literature cited by Miller et al. (2003) indicated that relative to random trees, bats selected roost trees that were taller, with a larger $\mathrm{DBH}$, and more open canopies. In our subsequent analysis, which incorporated the most recent data, the same 3 variables again were significant, but in addition the analysis indicates that roost trees were found in stands with significantly more snags per hectare than random trees and cavity roosts were closer to water than random trees. Even if some original data are limited (because of design or sample size), these marginal data are useful in a meta-analytic framework (Johnson 2002) and we argue that the consistency in our results is convincing evidence that these patterns are valid. Taken together, we argue that counter to the con- 


\section{Wildife Society Bulletin 2005, 33(3):1123-1132}

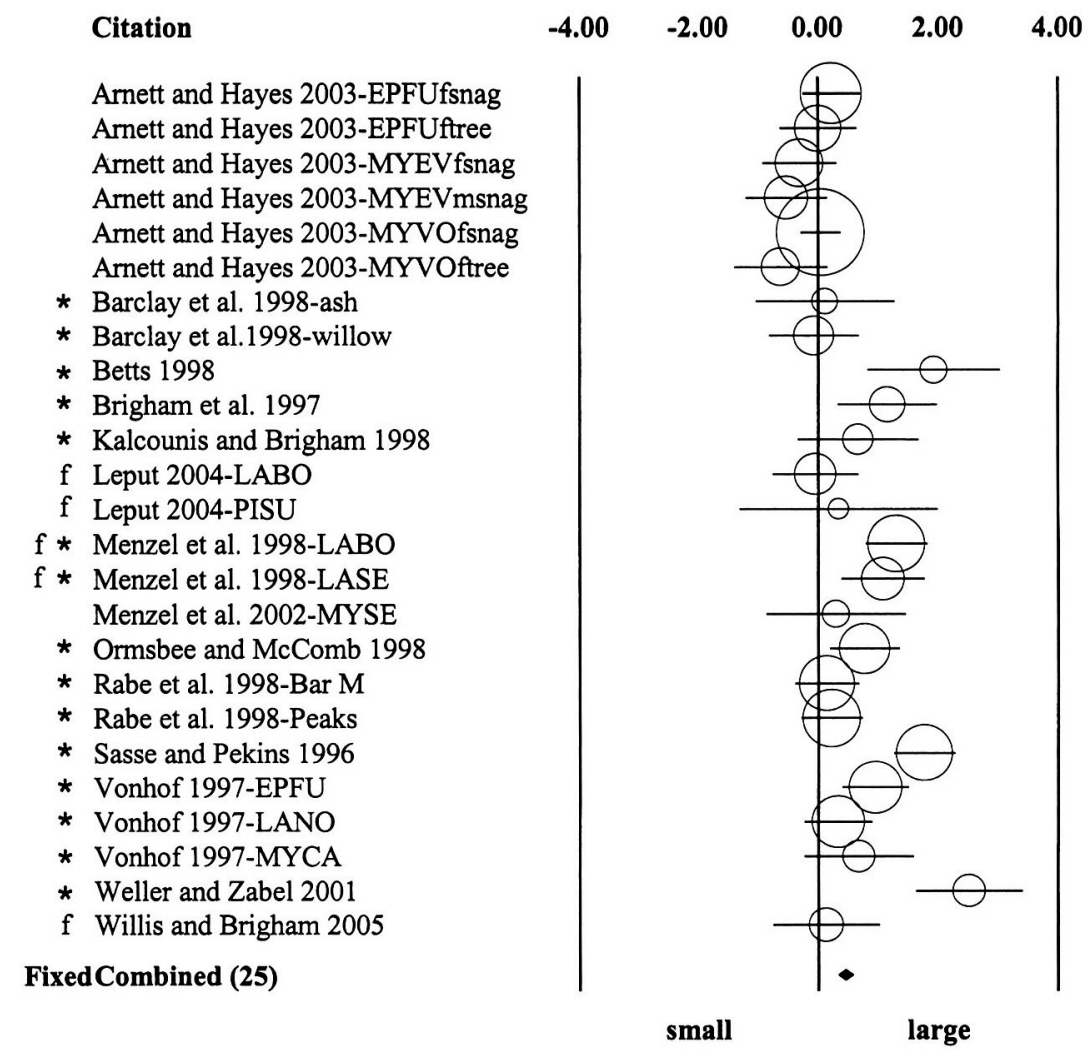

Figure 2. Schematic diagram of the meta-analysis for all studies that examined the height of roost and random trees. An explanation of the schematic is given in the legend for Figure 1.

tention of Miller et al. (2003), clear and consistent patterns can be distilled from the literature they reviewed in the context of bat use of tree roosts and that these results can guide harvesting prescriptions by forest managers. We do not suggest our results should replace efforts to further understand relations between bats and their environment, because many fundamental and applied research questions remain unanswered (Hayes 2003, Kunz and Lumsden 2003, Miller et al. 2003).

One reason the patterns of roost use by bats were so readily distilled by our analysis is that in the vast majority of studies, the same variables have been measured. This is largely due to early studies being used as a template in subsequent work. Despite the fact that there are some limitations in this traditional "roost vs. random" comparison (e.g., location of random trees often are in same stand and so cannot be used to look at stand-level differences and other questions related to scale; Miller et al. 2003), the consistency of available data made a meta-analytic technique appropriate and easy to interpret. Our confidence in the outcome of the analyses of data on roosting is enhanced by the similarity of results with the inclusion of additional studies not available to Miller et al. (2003).

We do not want our analysis to be perceived as representing the "last word" on roost-site selection, even though we argue it is evident that from a forest management point of view the current data are good and prescriptions for harvest can confidently incorporate information about type of roost structures needed by bats. Miller et al. (2003:35) contended, ". . . most researchers operate under the paradigm that roosts are the primary limiting factor for bats, although this has not been clearly demonstrated...." We feel it is more appropriate to suggest that roost sites are critical resources for bats; whether they are "the" primary limiting factor remains to be determined. Regardless, it is logical to suggest that without suitable roosts, the conservation of many forest species would be difficult. We argue that our analysis points to the types of structures bats prefer to roost in, and this information can be used as a guide for management so that these types of structures can be recruited in forests in the future. From the per- 


\section{Citation}

* Betts 1998

* Brigham et al. 1997

Broders and Forbes 2004-MYLUm

Broders and Forbes 2004-MYSEf

Broders and Forbes 2004-MYSEm

* Calahan et al. 1997-interior live

* Calahan et al. 1997-interior snag

* Campbell et al. 1996

* Kalcounis and Brigham 1998

* Lacki and Schwierjohann 2001

f Leput 2004-LABO

f Leput 2004-PISU

Menzel et al. 2002-MYSE

* Ormsbee and McComb 1998

* Rabe et al. 1998-Bar M

* Rabe et al. 1998-Peaks

* Sasse and Pekins 1996

* Vonhof 1997-EPFU

* Vonhof 1997-LANO

* Vonhof 1997-MYCA

* Weller and Zabel 2001

f Willis and Brigham 2005

Fixed Combined (22)

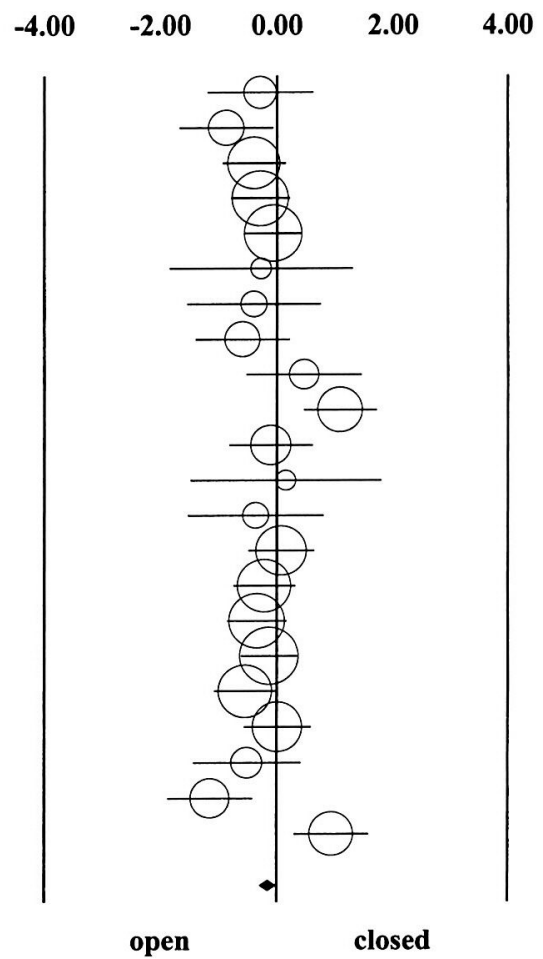

open closed

Figure 3. Schematic diagram of the meta-analysis for all studies that examined the percent canopy cover of roost and random trees. An explanation of the schematic is given in the legend for Figure 1.

\section{Citation}

Arnett and Hayes 2003-EPFUfsnag Arnett and Hayes 2003-EPFUftree Arnett and Hayes 2003-MYEVfsnag Arnett and Hayes 2003-MYEVmsnag Arnett and Hayes 2003-MYVOfsnag Arnett and Hayes 2003-MYVOftree

* Brigham et al. 1997

Broders and Forbes 2004-MYSEf

Broders and Forbes 2004-MYSEm

$\mathrm{f} *$ Hutchison and Lacki 2000

* Lacki and Schwierjohann 2001

* Ormsbee and McComb 1998

* Rabe et al. 1998-Bar M

* Rabe et al. 1998-Peaks

* Weller and Zabel 2001

FixedCombined (16)
Broders and Forbes 2004-MYLUm

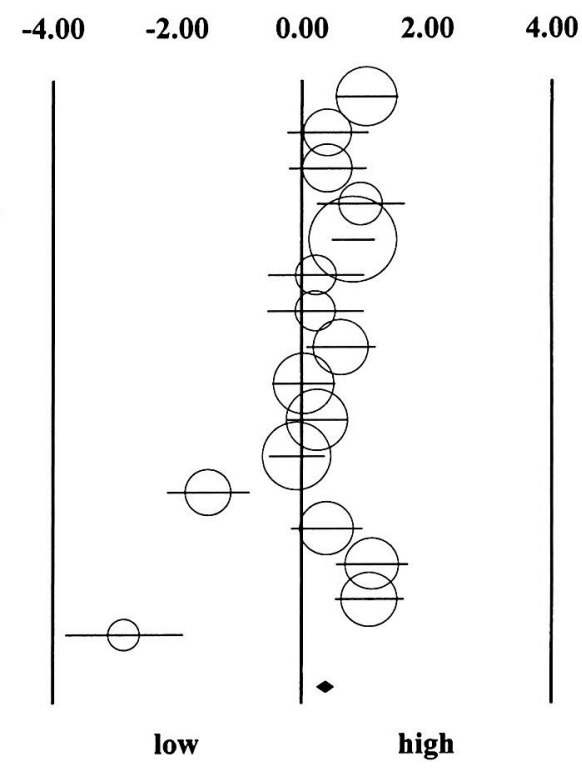

Figure 4. Schematic diagram of the meta-analysis for all studies that examined the density of snags in plots/stands that contained roost trees and plots/stands that contained random trees. An explanation of the schematic is given in the legend for Figure 1. 


\section{Wildife Society Bulletin 2005, 33(3):1123-1132}

\author{
Citation \\ * Brigham et al. 1997 \\ Broders and Forbes 2004-MYLUm \\ Broders and Forbes 2004-MYSEf \\ Broders and Forbes 2004-MYSEm \\ $f$ * Hutchison and Lacki 2000 \\ Menzel et al. 2002-MYSE \\ * Ormsbee and McComb 1998 \\ * Rabe et al. 1998-Bar M \\ * Rabe et al. 1998-Peaks \\ * Vonhof 1997-EPFU \\ * Vonhof 1997-LANO \\ * Vonhof 1997-MYCA \\ * Weller and Zabel 2001 \\ f Willis and Brigham 2005
}

Fixed Combined (14)

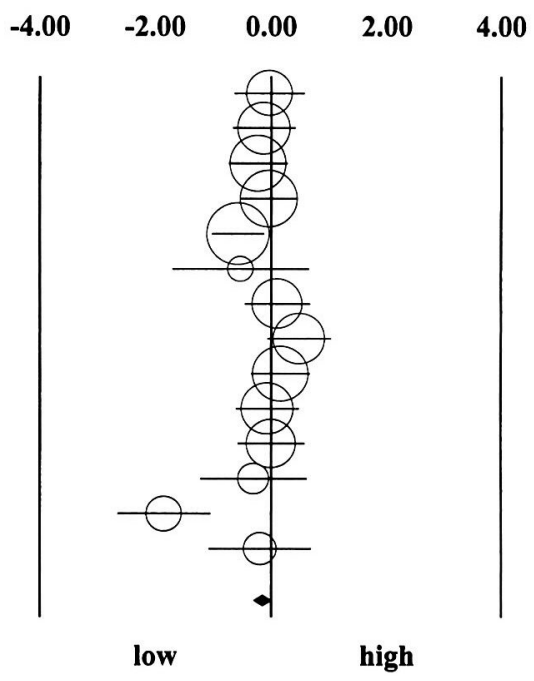

Figure 5. Schematic diagram of the meta-analysis for all studies that examined the density of live trees in plots/stands that contained roost trees and plots/stands that contained random trees. An explanation of the schematic is given in the legend for Figure 1.

spective of bat biologists, it remains unclear why bats choose the structures they do (Kunz and Lumsden 2003). We also contend that recent evidence suggesting that bats exhibit fidelity to a number of different trees in a small area using a fission/fusion model of roosting behavior (Cryan et al. 2001, Kerth and Konig 1999, Kerth et al. 2001a, Willis and Brigham 2004) warrants further attention, in the context of both forest management and bat biology.

In the broader perspective, the question remains as to whether patterns we report for North America also hold for other parts of the world where a number of studies have been done but forest structure and the species of trees present are different (e.g., Europe: Boonman 2000, Kerth et al. 2001b; Australia: Lunney et al. 1988, Law and Anderson 2000, Lumsden et al. 2002, New Zealand: O'Donnell and Sedgeley 1999, Sedgeley and O'Donnell 1999, Sedgeley 2003).

We attempted a similar meta-analytic approach to determine whether enough data are currently available to assess general pattern in the use of landscape space by foraging bats in forest ecosystems (Kalcounis-Ruppell et al. 2004 abstract). In contrast to patterns uncovered for roosting, our analysis suggests that a combination of small sample sizes (studies and data sets), inconsistencies in the variables measured, and variation by bats themselves makes distilling general patterns about spatial patterns of foraging not possible at present. The quan-

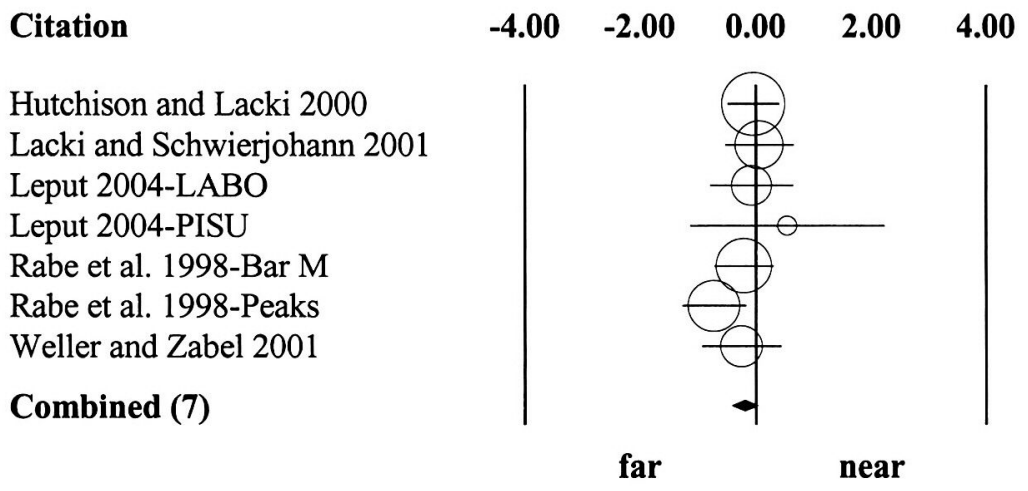

Figure 6. Schematic diagram of the meta-analysis for all studies that examined the distance to water of roost and random trees. An explanation of the schematic is given in the legend for Figure 1. 
tity and quality of data simply are not available for the same kind of meta-analytic approach to understanding foraging by bats in forest ecosystems. In contrast to studies on roost selection, this is due in part to the lack of a template that many studies have followed. Thus, in the context of foraging, we agree with Miller et al. (2003) that at present bat biologists are not in a position to advise forest mangers about harvesting prescriptions that will take into account foraging habitat requirements. Recommendations provided by Miller et al. (2003) will improve the utility of multiple data sets from different areas in the context of data interpretation and synthesis.

Acknowledgments. We are grateful to D. Miller, E. Arnett, and M. Lacki for prompting us to take on this analysis and discussion regarding our metaanalysis. We thank all of the authors who provided reports, theses, and other forms of original data for our analysis. Our work was supported by funds from the University of North Carolina at Greensboro to $M$. C. Kalcounis-Rüppell and a Natural Science and Engineering Research Council of Canada Discovery grant to R. M. Brigham. C. Willis and $C$.Turbill made helpful comments on an earlier version of the manuscript.

\section{Literature cited}

ARnetT, E. B., AND J. P. HAYES. 2003. Presence, relative abundance and resource selection of bats at multiple spatial scales in western Oregon. Unpublished final report to USGS-BRD, Cooperative Forest Ecosystem Research Program, Oregon State University, Corvallis, USA.

ARNQVIST G., AND D. WoOSTER. 1995. Meta-analysis: synthesizing research findings in ecology and evolution. Trends in Ecology and Evolution 10:236-240.

Barclay, R. M. R., P.A. Faure, And D. R. Farr. 1988. Roosting behavior and roost selection by migrating silver-haired bats (Lasionycteris noctivagans). Journal of Mammalogy 69: 821-825.

BARCLAY, R. M. R., AND R. M. BRighaM, EDITORS. 1996. Bats and forests symposium, October 19-21, 1995, Victoria, British Columbia, Canada. Research Branch, British Columbia Ministry of Forestry, Victoria, B. C. Working Paper 23/1996.

BETTS, B. J. 1998. Roosts used by maternity colonies of silverhaired bats in northeastern Oregon. Journal of Mammalogy 79:643-650.

BOONMAN, M. 2000. Roost selection by noctules (Nyctalus noctula) and Daubenton's bats (Myotis daubentonii). Journal of Zoology (London) 251:385-389.

Brigham, R. M., M. J. Vonhof, R. M. R. Barclay, and J. C. GWilliam. 1997. Roosting behavior and roost-site preferences of forest California bats (Myotis californicus). Journal of Mammalogy 78: $1231-1239$

BRODERS, H. G., AND G. J. Forbes. 2004. Interspecific and intersexu- al variation in roost-site selection of northern long-eared and little brown bats in the greater Fundy National Park Ecosystem, New Brunswick. Journal of Wildlife Management 68 : 601-610.

Callahan, E.V., R. D. Drobney, AND R. L. Clawson. 1997. Selection of summer roosting sites by Indiana bats (Myotis sodalis) in Missouri. Journal of Mammalogy 78:818-825.

Campbell, L.A., J. G. Hallett, and M.A. O'Connell. 1996. Conservation of bats in managed forests: use of roosts by Lasionycteris noctivagans. Journal of Mammalogy 77:976-984.

CRYAN, P. M., M.A. BOGAN, AND G. M.YANEGa. 2001. Roosting habits of four bat species in the Black Hills of South Dakota. Acta Chiropterologica 3:43-52.

FOSTER, R.W., AND A. KURTA. 1999. Roosting ecology of the northern bat (Myotis septentrionalis) and comparisons with the endangered Indiana bat (Myotis sodalis). Journal of Mammalogy 80:659-672.

GRINDAL, S. D. 1999. Habitat use by bats, Myotis spp., in western Newfoundland. Canadian Field-Naturalist 113:258-263.

Gurevitch, J., P. S. Curtis, AND M. H. Jones. 2001. Meta-analysis in ecology. Advances in Ecological Research 32: 199-247.

HAYES, J. P. 2003. Habitat ecology and conservation of bats in western coniferous forests. Pages 81-119 in C. J. Zabel, and R. G. Anthony, editors. Mammal community dynamics in coniferous forests of western North America: management and conservation. Cambridge University Press, Cambridge, United King dom.

Hutchinson, J.T., AND M. J. Lacki. 2000. Selection of day roosts by red bats in mixed mesophytic forests. Journal of Wildlife Management 64:87-94.

JOHNSON, D. H. 2002. The importance of replication in wildlife research. Journal of Wildlife Management 66:919-932.

Kalcounis, M. C., AND R. M. BRigham. 1998. Secondary use of aspen cavities by tree-roosting big brown bats. Journal of Wildlife Management 62:603-611.

Kalcounis-Rüppell, M. C., J. M. Psyllakis, And R. M. Brigham. 2004. Bats and forest stands: an empirical synthesis using meta-analysis. Abstract for Bats and Forests II conference held in Hot Springs, Arkansas. Organized by Bat Conservation International, 9-12 March 2004.

KERTH, G.,AND B. KÖNIG. 1999. Fission, fusion and nonrandom associations in female Bechstein's bats (Myotis bechsteinii). Behaviour 136: 1187-1202

KeRTH, G., M. WAGNER, AND B. KöNIG. 2001a. Roosting together, foraging apart: information transfer about food is unlikely to explain sociality in female Bechstein's bats (Myotis bechsteinit). Behavioural Ecology and Sociobiology 50 : 283-291.

Kerth, G., K. WeisSmann, AND B. KÖNIG. 2001b. Day roost selection in female Bechstein's bats (Myotis bechsteinii): a field experiment to determine the influence of roost temperature. Oecologia 126: 1-9.

KunZ,T. H., AND L. F. Lumsden. 2003. Ecology of cavity and foliage roosting bats. Pages 3-89 in T. H. Kunz and M. B. Fenton, editors. Bat ecology. University of Chicago Press, Chicago, Illinois, USA.

LACKI, M. J., AND J. H. SCHWIERJOHANN. 2001. Day-roost characteristics of northern bats in mixed mesophytic forests. Journal of Wildlife Management 65:482-488.

LAW, B. S., AND J. ANDERSON. 2000. Roost preferences and foraging ranges of the eastern forest bat, Vespadelus pumilus under two disturbance histories in northern New South Wales. Austral Ecology 24:352-367. 


\section{Wildlife Society Bulletin 2005, 33(3):1123-1132}

LEPUT, D. 2004. Eastern red bat (Lasiurus borealis) and Eastern pipistrelle (Pipistrellus subflavus) maternal roost selection: implications for forest management. Thesis, Clemson University, Clemson, South Carolina, USA.

Lumsden, L. F, A. F Bennett, and J. E. Silins. 2002. Selection of roost sites by the lesser long-eared bat Nyctopbilus geoffroyi and Gould's wattled bat Chalinilobus gouldii in south-eastern Australia. Journal of Zoology (London) 257:207-218.

LunNeY, D., J. Barker, D. Priddel, AND M. O'ConNell. 1988. Roost selection by Gould's long-eared bat, Nyctophilus gouldi Tomes (Chiroptera: Vespertilionidae), in logged forests on the south coast of New South Wales. Australian Wildlife Research 15: 375-384.

Menzel, M.A.,T. C. Carter, B. R. Chapman, and J. Laerm. 1998. Quantitative comparison of tree roosts used by red bats (Lasiurus borealis) and Seminole bats (L. seminolus). Canadian Journal of Zoology 76:630-634.

MENZEL, M.A., S. F. OWEN, W. M. FORD, J.W. EDWARDS, P. B. WOOD, B. R. ChapMAN,AND K.V. Miti.er. 2002. Roost tree selection by northern long-eared bat (Myotis septentrionalis) maternity colonies in an industrial forest of central Appalachian mountains. Forest Ecology and Management 155:107-114.

MULER, D. A., E. B. ARNETT, AND M. J. LACKI. 2003. Habitat management for forest-roosting bats of North America: a critical review of habitat studies. Wildlife Society Bulletin 31:30-44.

O'DONNELI, C. F. J., AND J. A. SEDGEIEY. 1999. Use of roosts in the long-tailed bat, Chalinolobus tuberculatus, in temperate rainforest in New Zealand. Journal of Mammalogy 80:913-923.

ORMSBEE, P. C.,AND W. C. MCCOMB. 1998. Selection of day roosts by female long-legged myotis in the central Oregon Cascade Range. Journal of Wildlife Management 62:596-603.

OSENBERG, C.W., O. SARNELLE, AND D. E. GoldBerg. 1999. Meta-analysis in ecology: concepts, statistics, and applications. Ecology 80: 1103-1104.

Rabe, M. J., T. E. Morrell, H. Green, J. C. DeVos, JR., ANd C. R. Miller. 1998. Characteristics of ponderosa pine snag roosts used by reproductive bats in northern Arizona. Journal of Wildlife Management 62:612-621.

SASSE, D. B., AND P. J. PeKIns. 1996. Summer roosting ecology of northern long-eared bats (Myotis septentrionalis) in the White Mountain National Forest. Pages 91-101 in R. M. R. Barclay and R. M. Brigham, editors. Bats and Forests Symposium, Organized by the British Columbia Ministry of Forests. October 19-21, 1995, Victoria, British Columbia, Canada.

SEDGELEY,J.A. 2003. Roost site selection and roosting behaviour in lesser short-tailed bats (Mystacina tuberculata) in comparison with long-tailed bats (Cbalinolobus tuberculatus) in Notbofagus forest, Fiordland. New Zealand Journal of Zoology 30:227-241

SEDGELEY,J.A.,AND C. F.J. O'DoNNELL. 1999. Roost selection by the long-tailed bat, Chalinolobus tuberculatus, in temperate New Zealand rainforest and its implications for the conservation of bats in managed forests. Biological Conservation 88:261-276.

VONHOF, M. J. 1997. A survey of the abundance, diversity, and roost-site preferences of bats in the Pend D'Oreille Valley, British Columbia. Unpublished report for The Columbia Basin Fish and Wildlife Compensation Program.

WELLER,T.J.,AND C.J. ZABEL. 2001. Characteristics of fringed myotis day roosts in northern California. Journal of Wildlife Management 65:489-497.

WILus, C. K. R., AND BRIGHAM, R. M. 2004. Roost switching, roost sharing and social cohesion: forest-dwelling big brown bats, Eptesicus fuscus, conform to the fission-fusion model. Animal
Behavior 68:495-505.

WILUS, C. K. R, AND R. M. BRIGHAM. 2005. Physiological and ecological aspects of roost selection by reproductive female hoary bats (Lasiurus cinereus). Journal of Mammalogy 86:85-94.

\section{Matina Kalcounis-Rüppell} (right) is an assistant professor in the Biology Department at the University of North Carolina at Greensboro. She received her B.Sc. and M.Sc. degrees from the University of Regina (1993 and 1995 respectively) and her Ph.D. from the University of Western Ontario (2001). She was a Post-Doctoral Fellow at the Museum of Vertebrate Zoolo-

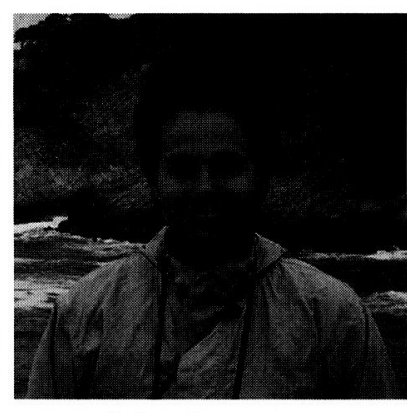
gy at the University of California, Berkeley during 2001-2003 Her research interests include the behavior, ecology, and energetics of North American bats and Peromyscine rodents. Matina is a

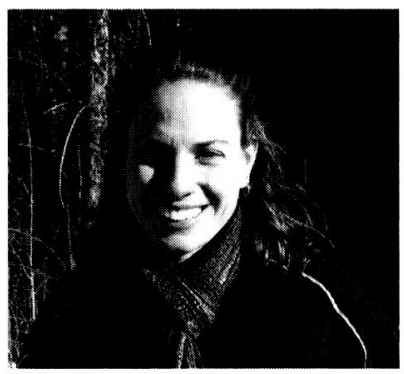
past member of the Western Section of The Wildlife Society and is a current member of its North Carolina Chapter. She sits on the Board and is President-Elect of the Southeastern Bat Diversity Network. Jennifer Psyllakis (left) is a Ph.D. candidate at the University of Northern British Columbia in the Natural Resource Environmental studies program. Her research involves modeling the relationship between wildlife and structural aspects of forests at multiple scales and approaches to managing wildlife diversity on multi-use landscapes. She received her B.Sc. in wildlife resources from McGill University (1997) and her M.Sc. in biology, studying aspects of roosting and foraging ecology of bats, from the University of Regina (2001) She has been a member of The Wildlife Society since 2000 Mark Brigham (right) is a professor in the Biology DepartTrEeth at the 'Utituetsitry of Regi-

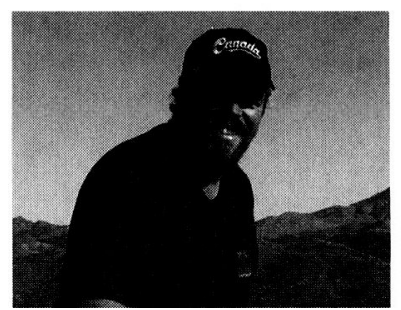
na. He received his B.Sc. degree from Queens University (1983), his M.Sc. from Carleton University (1985), his Ph.D. at York University (1988), and did a post-doctoral fellowship at the University of Calgary. His areas of professional interests include the behavioral and physiological ecology of insect-eating bats and nightjars and the conservation biology of listed species such as piping plovers, sage grouse, Sprague's pipits, burrowing owls and pallid bats. He has been a member of The Wildlife Society since 1999 and enjoys sipping fine Australian shiraz while reading papers in the Society's journals.

Associate editor: Nilon 